\title{
The Investigation of the Ardales Cave, Spain - 3D Documentation, Topographic Analyses, and Lighting Simulations based on Terrestrial Laser Scanning
}

\author{
DIRK HOFFMEISTER ${ }^{1 *}$, STEFAN ZELLMANN ${ }^{2}$, ANDREAS PASTOORS $^{3}$, \\ MARTIN KEHL ${ }^{1}$, PEDRO CANTALEJO ${ }^{4}$, JO'SÉ RAMOS ${ }^{5}$, \\ GERD-CHRISTIAN WENIGER ${ }^{3}$ AND GEORG BARETH ${ }^{1}$ \\ ${ }^{1}$ Institute of Geography, University of Cologne, Albertus-Magnus-Platz, 50923 Cologne, Germany \\ ${ }^{2}$ Chair of Computer Science, University of Cologne, Albertus-Magnus-Platz, 50923 Cologne, Germany \\ ${ }^{3}$ Neanderthal Museum, Talstrasse 300, 40822 Mettmann, Germany \\ ${ }^{4}$ Museo Municipal de la Historia y las Tradiciones de Ardales, Avda. de Málaga, $n^{\circ} 1$-29550, Ardales, \\ (Málaga), Spain \\ ${ }^{5}$ Universidad de Cádiz, Facultad de Filosofía y Letras, Departamento de Historia, Geografía y Filosofía, \\ 11003 Avda. Gómez Ulla sn, Cádiz, Spain
}

\begin{abstract}
This contribution shows the application of terrestrial laser scanning in an integrative approach for the documentation and analyses of the Ardales Cave, southern Spain, which is in many respects an important geoarchaeological site. For the survey of the cave, a combination of the Riegl LMS Z420i laser scanner with a real-time kinematic global positioning system (RTK-GPS) from Topcon and further tachymetric measurements were used. The achieved threedimensional (3D) model of the cave and the surrounding hill documents the current topography and dimensions of the cave. Additional geoarchaeological data were successfully integrated in a 3D geographical information system (GIS) database and high-resolution records of a structured-light scanner were combined with the 3D model of the cave. The 3D model is further used for the estimation of the ceiling thickness that reveals areas for additional entrances. Lighting simulations based on path tracing were conducted for the determination of areas that are reached by natural direct or indirect light. In this case, the weight and size of the instrument was a logistic constraint to reach certain areas and to achieve a complete model of the cave. Overall, the method is feasible for the documentation of this cave and the investigations based on the derived 3D models. Copyright (C) 2015 John Wiley \& Sons, Ltd.
\end{abstract}

Key words: LiDAR; caves; geoarchaeology; lighting simulation; 3D model; 3D GIS

\section{Introduction}

Surveying of caves by terrestrial laser scanning (TLS) is a reliable approach to derive an accurate threedimensional (3D) model of such sites, which can be used for further analysis and documentation purposes (Buchroithner and Gaisecker, 2009; Rüther et al., 2009). More generally, TLS is an important tool for the investigation of geoarchaeological sites and the documentation of cultural heritage (Remondino, 2011).

* Correspondence to: D. Hoffmeister, Institute of Geography, University of Cologne, Albertus-Magnus-Platz, 50923 Cologne, Germany. E-mail: dirk.hoffmeister@uni-koeln.de
TLS is based on light detection and ranging (LiDAR) and provides highly accurate and dense 3D point clouds of objects (Heritage and Large, 2009). The method is applicable on different scales, areas, and accuracies. The technology can be used on airborne platforms, known as airborne laser scanning (ALS), on mobile platforms, known as mobile laser scanning (MLS), as well as on terrestrial platforms, known as TLS. Various application areas, like topographic surveys, forestry, and as-built documentation exist (Vosselman and Maas, 2010). For example, ALS is able to detect and document archaeological sites in forests and shallow waters (Doneus et al., 2008, 2013; Shih et al., 2014). 
Caves contain vulnerable remains, for example footprints and cave art left by prehistoric and historic humans, and thereby represent valuable archives of archaeological and anthropological research. Given their complex topography, caves have been recently documented by laser scanning, which shows a promising applicability within the harshest environmental conditions for geodetic measurements. For instance, the complete and accurate model of the complex Dachstein south-face Cave, Austria, acquired by TLS, with several parts only reachable by climbing and roping of the instrument, has been highly valuable for karst hydraulic modelling and visualization purposes (Buchroithner and Gaisecker, 2009). A combined approach of TLS, photogrammetry and high-resolution records of a scan arm was used to document the cave Les Fraux, France (Grussenmeyer et al., 2012). The active, fast, and automatic surveying by TLS was important for the documentation of the Wonderwerk Cave, South Africa in contrast to conventional surveying and photogrammetry (Rüther et al., 2009). Surveying by a theodolite was used in this case for the determination of targets inside the cave and for an outside topographic survey. Further research has been conducted by combining close range photogrammetry and TLS for the documentation of rock art in caves (González-Aguilera et al., 2009a, 2009b, 2011; Lerma et al., 2010).

More generally, most of the available remote sensing methods are employed for the accurate documentation and description of geoarchaeological sites and cultural heritage (Remondino, 2011). A combined approach is most often the best solution. For example, the combination of TLS and unmanned aerial vehicle (UAV)photogrammetry was used for a survey of Pichango Alto, Peru (Lambers et al., 2007). All data is combinable in 3D geographical information system (GIS) environments for the exploration, analysis, reconstruction and representation of the acquired data (Bruno et al., 2010; Katsianis et al., 2008; Rua and Alvito, 2011). However, several problems need to be solved, which are for example the storage, exchange, quality control and metadata description of 3D models, as well as specific problems with each surveying method (Remondino, 2011).

In this contribution a TLS survey of the Ardales Cave, Spain was conducted within the framework of an interdisciplinary research project (CRC806, 2014). The focus of the project at this site is on the reconstruction of the original topographic situation of the Ardales Cave during different prehistoric periods. Therefore, an accurate 3D model is needed. The TLS survey was conducted in order to document the current topography of the cave as a base for further analyses. Furthermore, the data derived from this survey is used to provide a base for a 3D-cave information system, which integrates all geological and archaeological data. In addition, areas for further entrances are estimated by a comparison of the inside and outside area and the 3D model of the cave is the base for a new lighting simulation, which reveals areas probably reached by daylight.

\section{Methods}

\section{The Ardales Cave}

The complexly structured Ardales Cave (N 36 52'22', W $4^{\circ} 49^{\prime} 44^{\prime \prime}$ ) is located in the south of Spain (Figure 1). Surrounded by various other archaeological sites near the Strait of Gibraltar, this region is of specific interest for prehistoric research. A still open question is the human dispersal across the Strait of Gibraltar, which may have acted either as a bridge or barrier (Richter et al., 2012). In addition, southern Iberia is discussed as a potential last refuge of Neanderthals, because radiocarbon dates apparently document their prolonged survival until about 28 ka BP (Blain et al., 2013; Finlayson et al., 2006; Jennings et al., 2011). However, these young dates are a matter of dispute (Kehl et al., 2013; Wood et al., 2013).

For the Ardales Cave, several findings prove the repeated use by prehistoric humans, such as 250 panels of rock art (paintings and engravings), as well as bones and artefacts distributed on the cave floor (Cantalejo et al., 2006; Cantalejo and Mar Espejo, 2013). The cave can be subdivided into several halls and galleries including the grand hall and the Galerías del Calvario and del Arquero in the lower part of the cave. Its upper part, the Galerías Altas, served as a burial place, which is nowadays only reachable by rock climbing (Ramos et al., 1992). At least one or several additional entrances possibly existed to allow these areas to be reached safely. Thus, besides an accurate recording, mapping and modelling of the cave, it was an additional task to find evidence for the hypothesis of further entrances.

\section{Survey of the outside and inside area of the cave}

For an entire 3D model of the cave and the surrounding area, the interior of the cave and the outside hill were surveyed by TLS. For this purpose, we used the TLS LMS-Z420i from Riegl, Austria (Riegl LMS GmbH, 2014). This solid device is characterized by time- offlight range detection with an accuracy of $0.6 \mathrm{~cm}$ (Kersten et al., 2009) and a maximum range of 1,000 m. For each scan, a resolution of $0.8 \mathrm{~cm}$ at a distance of 


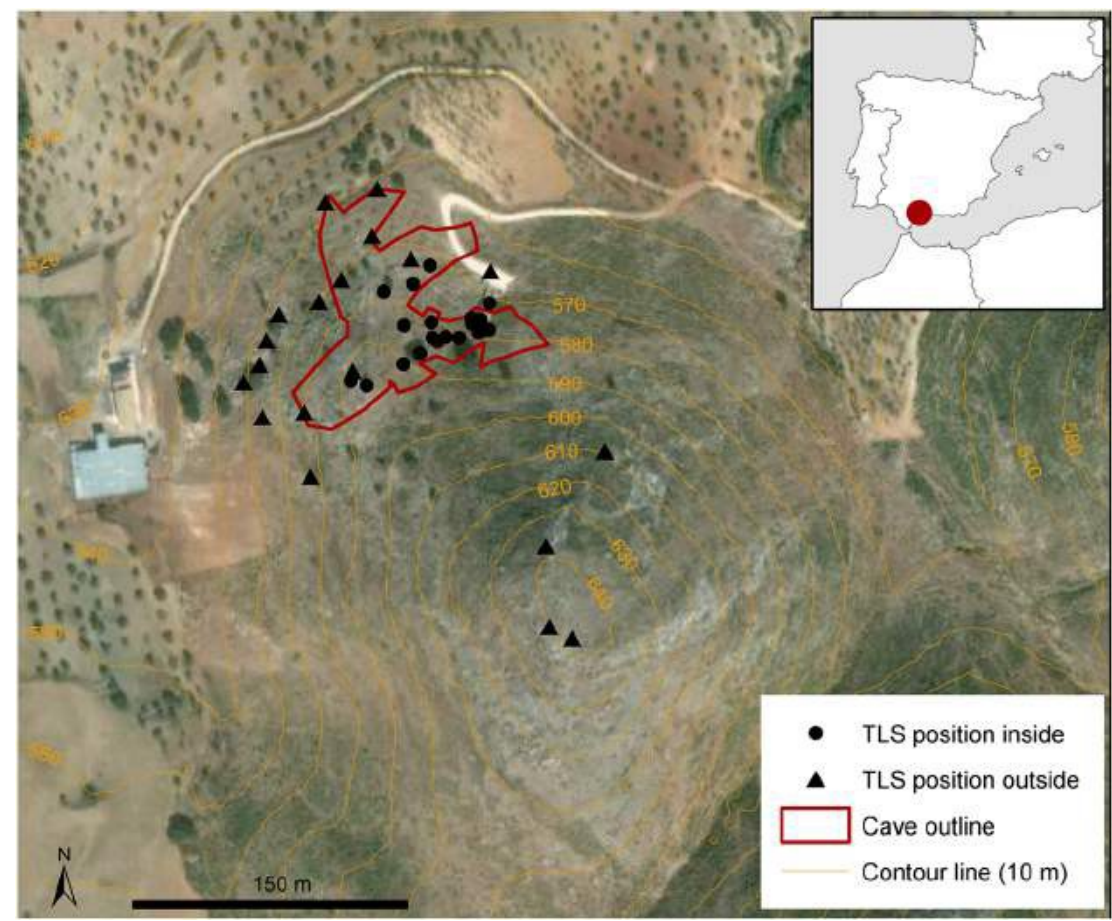

Figure 1. Location of the Ardales Cave, its outline, and all scan positions inside and outside the cave. Two further scan positions were located on the opposite hills to the northwest and south. Imagery: @2012 Google, Digital Globe, 21 September 2009. This figure is available in colour online at wileyonlinelibrary.com/journal/arp

$10 \mathrm{~m}$ was selected, as a maximum resolution for a full scan (field of view: $80^{\circ}$ by $360^{\circ}$ ), resulting in an approximate point spacing of 1 to $2 \mathrm{~cm}$. The TLS is used in combination with a highly accurate real-time kinematic global positioning system (RTK-GPS) HiPer Pro from Topcon, Japan. The RTK-GPS was applied for the accurate determination of the outside scan positions. The relative accuracy of the RTK-GPS is $\sim 1 \mathrm{~cm}$ for both directions in regard to the base station and shows an absolute accuracy of $\sim 1.5 \mathrm{~m}$ in the horizontal and vertical direction. This accuracy was previously tested with known coordinates of surveying points from the ordnance survey, as stated by the manufacturer, and is within the range of such devices (Seeber, 2003). As the relation of the RTK-GPS antenna and the laser beam output is known, the origin of the laser is determined. For the orientation of the point cloud a further reference target is recorded. Here, we used reflectors on ranging poles, which were each directly recorded by the RTKGPS and easily detected by the scanner. This process is known as backsighting or resection in order to determine the initial position and orientation of the point cloud (Mårtensson et al., 2012).

The TLS device was additionally equipped with a digital camera of type Nikon D200, which was mounted on the head of the laser scanner to take pictures. The lens is a calibrated Nikkor $20 \mathrm{~mm} \mathrm{f/2.8D}$ with a fixed focus set to infinity. For all inside pictures the camera was set to f/3.2, ISO $200,2-10 \mathrm{~s}$, which results in an operational range of $\sim 3.5 \mathrm{~m}$ to infinity. For all outside pictures the camera was set to $\mathrm{f} / 8$ to $\mathrm{f} / 11$, ISO 100 , $1 / 100-1 / 250 \mathrm{~s}$, depending on the current illumination. These pictures can be used for the colourization of the pointclouds by assigning red-green-blue (RGB)-values to each point, for direct measurements in the pictures, and for texturing final 3D models, as the relative orientation between the camera and the scanner is known. However, more extensive picture recording and additional illumination would be needed for high quality texturing.

At the outside area 21 scan positions were established, each georeferenced by the RTK-GPS measurements (WGS 1984, UTM 30N). The inside area of the cave was surveyed from 19 scan positions, most of them with additional, tilted scan positions for a full coverage. Supplementary illumination by an external light mounted onto the camera (type: NPE Light $\mathrm{CN}-240 \mathrm{CH}$ ) was necessary to achieve better pictures from the mounted camera. Panoramic pictures from selected inside positions, derived from the original pictures (software: Microsoft ICE) were manually enhanced in terms of contrast and illumination (software: Adobe Photoshop CS 5). For the inner parts of the cave, the registration of the scan positions was enabled by an indirect registration with smaller targets. A connective registration between the outside RTK-GPS measurements and the 
inside local surveying network (Trimble M3 1" total station) was established at two scan positions. All further scan positions of the inside survey were connected to these initial scan positions. An accurate integration of all previously measured geoarchaeological data measured by the total station, which comprises all drilling locations, georadar profiles, and further measurements, was possible by the transformation established from measurements of six identical points in both systems.

In several sections of the cave, four engravings were measured by a structured-light scanner, type Breuckmann smartSCAN ${ }^{3 \mathrm{D}}$-DUO, for a high-resolution representation (resolution: $0.1-0.35 \mathrm{~mm} /$ pixel) (Tusa et al., 2013). Restrictions in the cave prevented the use of reflectors on the walls. Thus, a point cloud to point cloud registration (software: CloudCompare) was used to achieve an accurateintegration of these datasets. The pictures of the TLS camera were utilized to texture these detailed models.

\section{Post-processing of the TLS data}

The TLS data for the entire 3D model of the cave was post-processed in several steps (software: RiSCAN PRO) that are the georeferencing of all data, the removal of obstructions and noise, the modelling, and all further data extraction. The registration of each scan position was accomplished by georeferencing every point cloud. Thus, the outside positions were assigned with the direct measurements of the RTK-GPS measurements and the position of one reflector for the orientation. Similarly, the inside initial positions were assigned with the georeferenced targets from the transformed tachymeter readings and each further inside scan position was registered to these initial scan positions by four or more identical targets. Finally, the ICP (iterative closest point)-algorithm (Besl and McKay, 1992), which is implemented in the scanner's software as multi-station adjustment (MSA) enhanced the registration. The colourization of each point within the point clouds was possible by assigning the RGB-values of the pictures taken by the digital camera. For the inside positions, selected original pictures were manually enhanced in terms of contrast and illumination.

After removing vegetation, noise, and further obstructions from the outside scan position data, a digital elevation model (DEM) with a resolution of $20 \mathrm{~cm}$ was interpolated. The 3D model of the inside area was computed by triangulation and an outer surface extraction with a triangle edge length of $10 \mathrm{~cm}$ for the generation of a water-tight 3D model of the entire cave. An alternative 3D cave model of the entrance area without the entrance building was established by manually removing all points of this building, the entrance door and certain walls. For all areas within the cave further 3D models, plans and cross-sections can be derived from this 3D model of the cave.

The complete 3D models of the cave and the outside hill were used to derive a ground plan of the cave and older maps of the cave were additionally considered. For further indications of cave entrances, the outside model and the inside upper shape of the cave were compared by building the difference that reflects the ceiling thickness. The inside ceiling was derived by a filter regarding only the maximum points of the cave area within a cell size of $20 \mathrm{~cm}$. Thus, two raster datasets are compared.

Additionally, all collected data were combined, as the transformation of both measurement systems, RTK-GPS and tachymetric measurements, is enabled. Thus, the data, such as the 3D models, archaeological measurements, georadar profiles and drilling locations, were integrated in a 3D GIS database for easy and comprehensive access for all project participants. This database is a file geodatabase (ESRI Inc., 2014), mainly structured by the input sources. The different 3D models were exported as collada files and imported as a 3D multi-patch feature class. Likewise, measurement data were imported as different 3D feature classes, and DEMs as well as imagery as raster data.

\section{Lighting simulation}

To achieve further insight into different lighting conditions, a physically inspired lighting simulation was conducted based on a tessellated version of the 3D model of the cave with the reconstructed ancient entrance area. In general, lighting simulations aim at solving the rendering equation (Kajiya, 1986):

$$
L_{o} \partial x ; w_{0} \mathbf{P} 1 / 4 L_{e} \partial x ; w_{0} \mathbf{P} \mathbf{p} \int \rho ð x ; w_{0} ; w_{i} \mathbf{P} L_{i} \partial x ; w_{i} \mathbf{P} d w_{i}
$$

where $L_{o}$ is the intensity of the light leaving each position $x$ in direction $\omega_{o}, L_{i}$ is the intensity of the incident light at $x$ from direction $\omega_{i}, L_{e}$ is the emitted light intensity in direction $\omega_{0}$ and $\rho$ is a bidirectional reflectance distribution function (BRDF) that models the physical properties of incident light from direction $\omega_{i}$ that is reflected into direction $\omega_{0}$. Because all light that is scattered to and from position $x$ must be integrated over a unit hemisphere $\Omega$, the rendering equation for the general case cannot be solved analytically. The path tracing algorithm, which was also proposed by Kajiya (1986), originates from geometric optics. It solves the rendering equation by stochastically sampling the hemisphere over positions where rays hit a surface by sending additional, secondary rays and accumulating 
light intensity along the path. BRDFs can be used to model real-world materials to an arbitrary degree of complexity. Furthermore, surface properties like those of stones can be approximated using diffuse BRDFs that sample each direction over the hemisphere with equal probability. For simplicity, all light entering through the entrance was assumed to be of equal intensity. Fully converged, the algorithm produces images that faithfully depict the radiance at each position of the cave due to direct and indirect lighting. The OpenCL-based simulation was integrated as a plugin into the rendering module of the scientific visualization software COVISE (Rantzau et al., 1996). COVISE is used to drive interactive visualizations in virtual environments.

\section{Results}

A 3D model of the Ardales Cave and the outside hill (Figure 2) was derived from the accurate TLS measurements by 61 single scans of 21 outside and 19 inside scan positions with additional tilted scans that sum up to $\sim 244$ million single point measurements. The area of the cave shows an extent of $\sim 115 \mathrm{~m}$ in a southwestern direction and a maximum width of about $50 \mathrm{~m}$. The great hall lies about $20 \mathrm{~m}$ below the entrance with a ceiling height of $\sim 20 \mathrm{~m}$. Similar ceiling heights are depicted for the corridor at the Galerías Altas.

Accurate models of specific inner areas have been generated for further analysis and visualization purposes. All data is combined in a 3D GIS (Figure 2) that can be used by all project participants for orientation and visualization purposes, as well as for geoscientific analyses, such as the derivation of slope and aspect. Furthermore, the data of the structured-light scanner was successfully integrated into the model (Figure 3).
The point cloud based registration shows a mean distance of $8 \mathrm{~mm}$ (standard deviation: $3 \mathrm{~mm}$ ). Important panels of cave art, can now be visualized in the corresponding cave environment and context. The detailed view in Figure 4 shows the prehistoric engravings recorded with the structured light scanner $(0.1 \mathrm{~mm} / \mathrm{pixel})$. In the centre a flamingo is depicted, superimposed with the drawing of panel IV.C.4 (Cantalejo et al., 2006: 184).

In order to detect areas that may contain further entrances, ventilation or illumination, the model of the cave and the outside hill was analysed. The comparison of the cave ceiling and the outside area revealed the ceiling thickness (Figure 5), which ranges from 8 to $48 \mathrm{~m}$. The error of this computation lies within the overall error of the measurements $(1 \mathrm{~cm})$ and slight alterations by the interpolation of the outside DEM. The entrance area, the main hall, and the Galería del Arquero show a ceiling thickness of about $8 \mathrm{~m}$, the most south-western point a ceiling thickness of about $15 \mathrm{~m}$, whereas the central parts of the cave reveal a ceiling thickness of up to $48 \mathrm{~m}$. Several further areas of the cave are not covered, as these areas were not reachable with the specific TLS device. The base level of the Galerías Altas is estimated by the entrance point at the end of a fixed ladder (Figure 5). Further areas, such as the extent of the Galerías Altas, are digitized from older maps of the cave.

For the reconstruction of the prehistoric environment and the perception of cave art, natural lighting and artificial illumination are key issues. The entrance to the cave, which is nowadays protected by an entrance building, was virtually reconstructed by removing this man-made object (Figure 6).

Thus, for the ensuing analysis this reconstructed entrance area has been taken into consideration. The



Figure 2. Model of the cave (dark grey) and the surrounding hill (light grey) with $10 \mathrm{~m}$ contour lines (brown). The models were acquired by terrestrial laser scanning (TLS) measurements and integrated with other data in a three-dimensional (3D) geographical information system (GIS). Red dots mark scan positions, black dots mark drilling locations and red lines show georadar transects. This figure is available in colour online at wileyonlinelibrary.com/journal/arp 


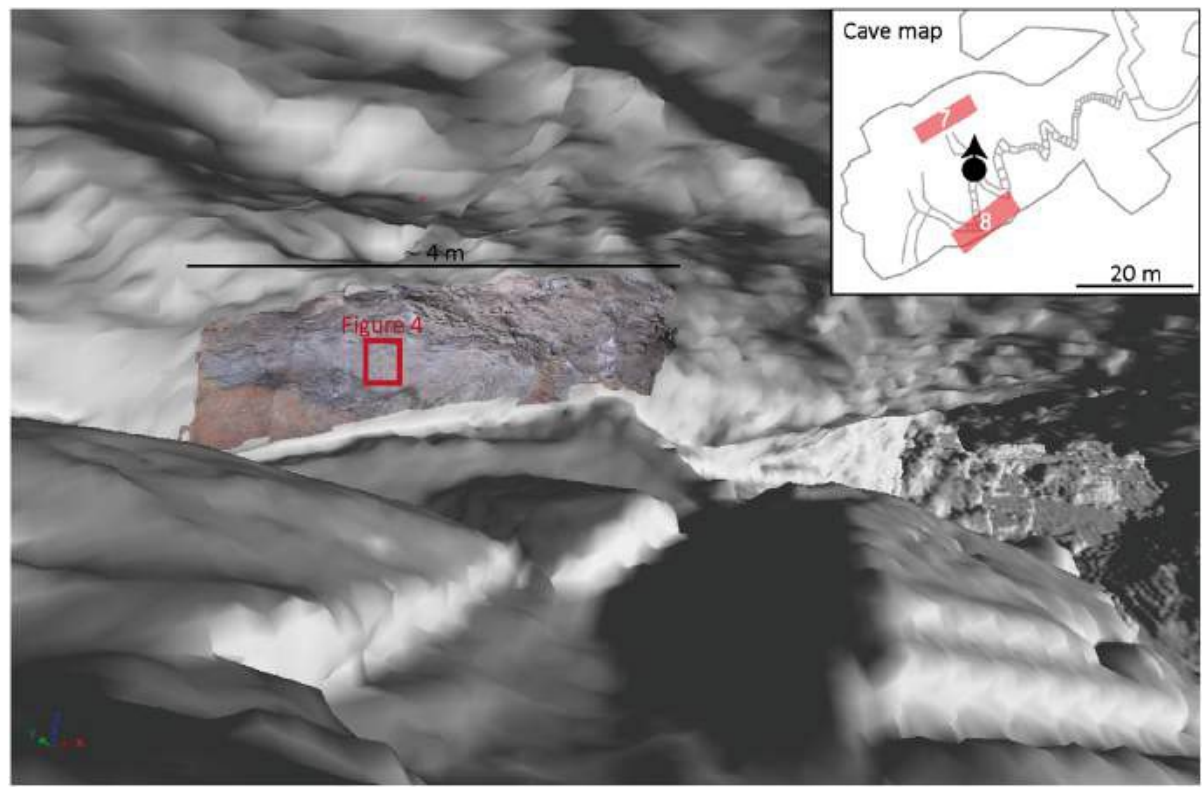

Figure 3. Part of the 3D cave model with the accurately positioned and textured high resolution scan of the structured-light scanner. The viewing position and direction is marked in the cave map by the dot and arrow. The geoarchaeological zone 7 shows important engravings on the wall of the cave. The detailed view is shown in Figure 4. This figure is available in colour online at wileyonlinelibrary.com/journal/arp

whole model has a chosen edge length of $10 \mathrm{~cm}$, resulted in a file consisting of $\sim 1$ million polygons and a file size of $\sim 350 \mathrm{MB}$, useable by mid-grade desktop computers. Higher resolutions, in particular for specific parts are possible. Generally, line-of-sight relations between the entrance area and the grand hall were revealed. A narrow direct line of sight exists from the entrance area to the ground floor of the grand hall. Here, these and other positions were observed by the lighting simulation (Figure 7). For that, the position and orientation of the virtual camera were manually selected to determine the innermost viewpoints, where either directly or indirectly scattered sunlight is visible. These positions and the viewing direction are marked

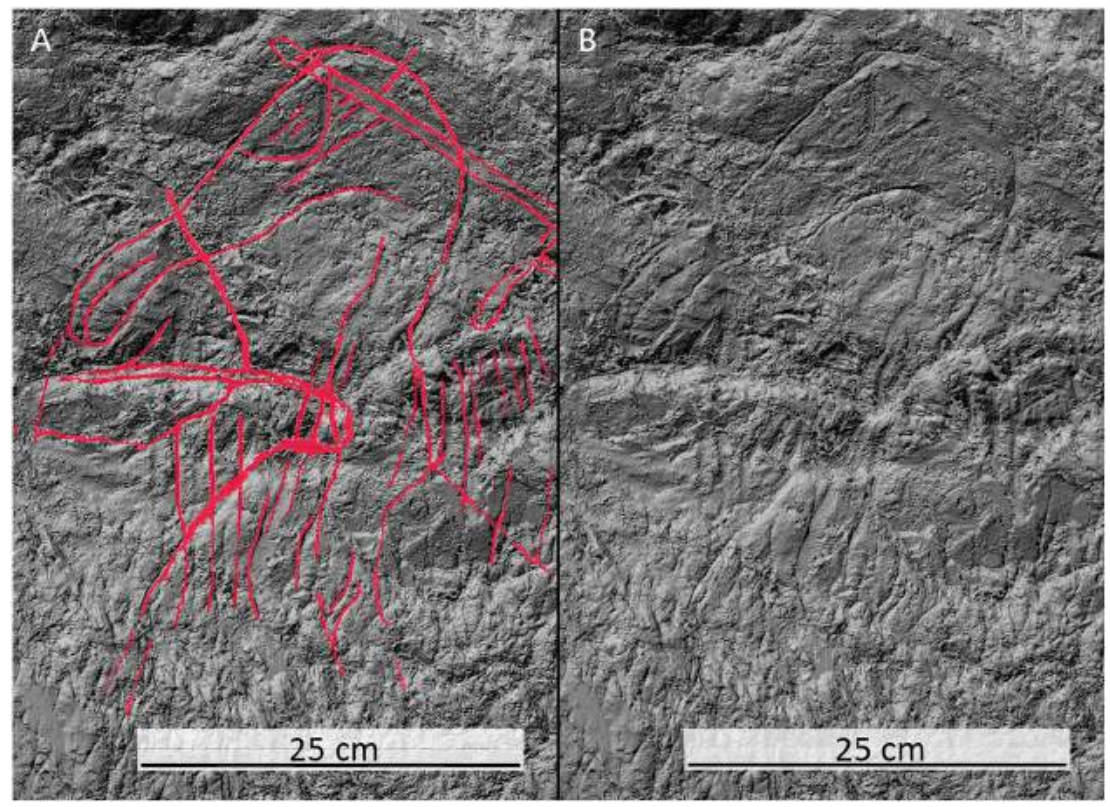

Figure 4. The detailed view of Figure 3 reveals the prehistoric engravings recorded with the structured light scanner ( $0.1 \mathrm{~mm} / \mathrm{pixel})$. A flamingo (A and B) is depicted, superimposed with the drawing of panel IV.C.4, based on Cantalejo et al. (2006: 184). This figure is available in colour online at wileyonlinelibrary.com/journal/arp 


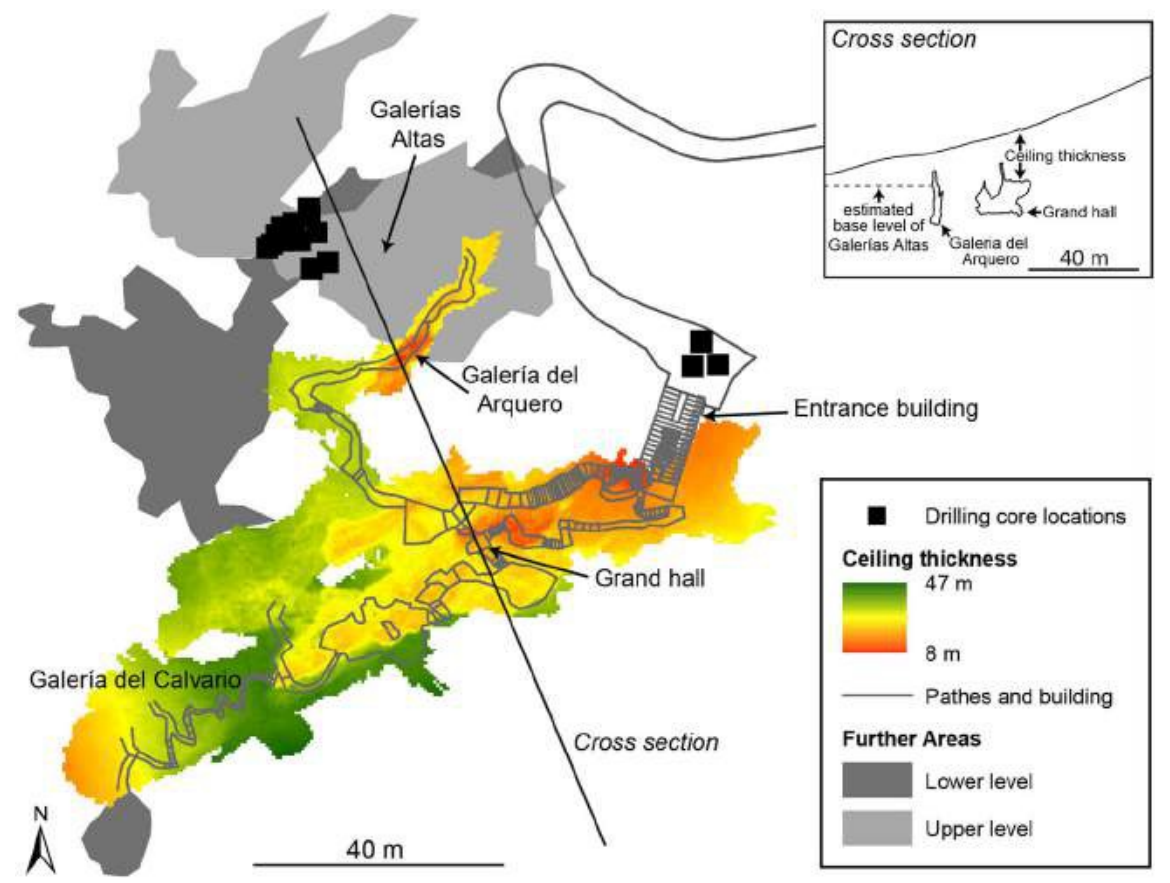

Figure 5. Map of the Ardales Cave. The ceiling thickness was determined by comparing the inner and outer 3D model. Paths and outlines of the entrance building were derived from the point cloud, and further areas were estimated from old maps. This figure is available in colour online at wileyonlinelibrary.com/journal/arp

in the cave map of Figure 7. The simulation revealed that no direct sunlight could possibly reach the grand hall (Figure 7C, 7D). Direct sunlight is only observable at the position nearby the reconstructed entrance (Figure 7A, 7B).

\section{Discussion}

Overall, the measurements of the Ardales Cave showed that the TLS method is an accurate and reliable tool to support geoarchaeological surveys of caves.
This is also acknowledged by other authors (Buchroithner and Gaisecker, 2009; Rüther et al., 2009) and for other surveys (Zielhofer et al., 2012). The solid laser scanner and the other required equipment was reliably usable in the cave sites, which was also noticed by Buchroithner and Gaisecker (2009) for the same type of scanner. No power supply line was necessary.

In this case, an accurate georeference was established by using the RTK-GPS solution in combination with the reflectors on ranging poles for the outside areas. The absolute accuracy of $\sim 1.5 \mathrm{~m}$ can be further enhanced by precise point positioning (PPP), the

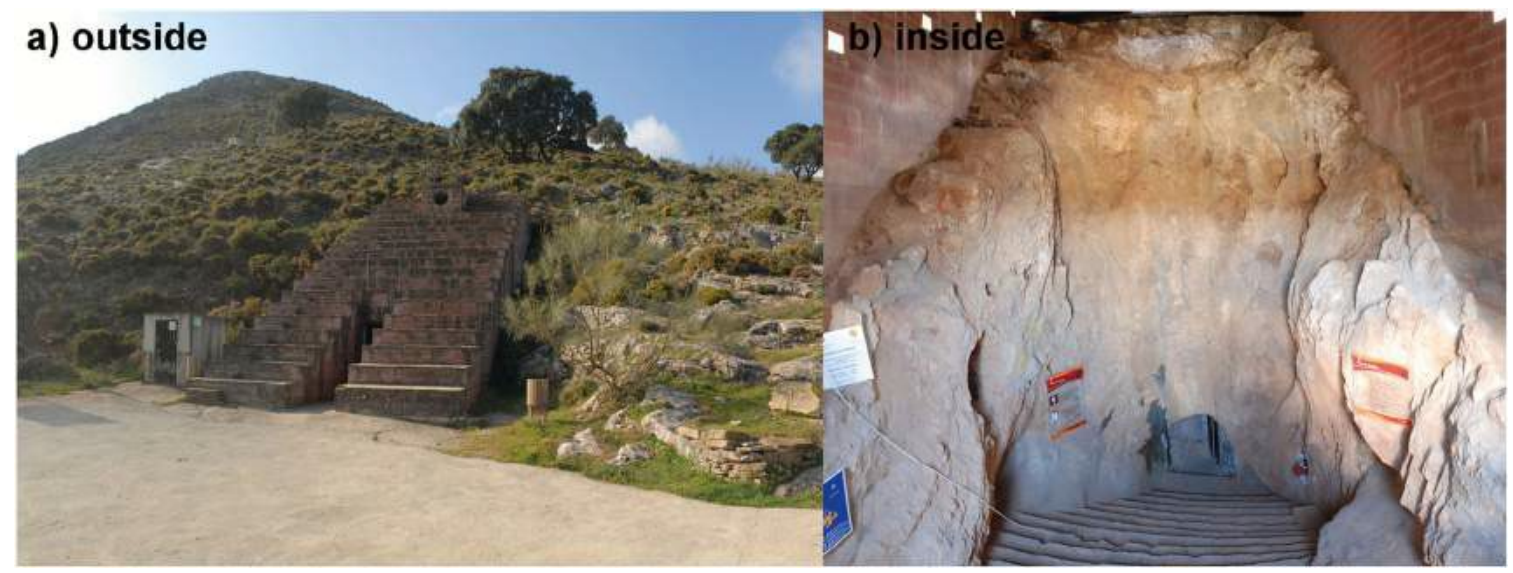

Figure 6. Panoramic picture of the entrance area with the building that was virtually removed together with the inside door to conduct the lighting simulation. This figure is available in colour online at wileyonlinelibrary.com/journal/arp 

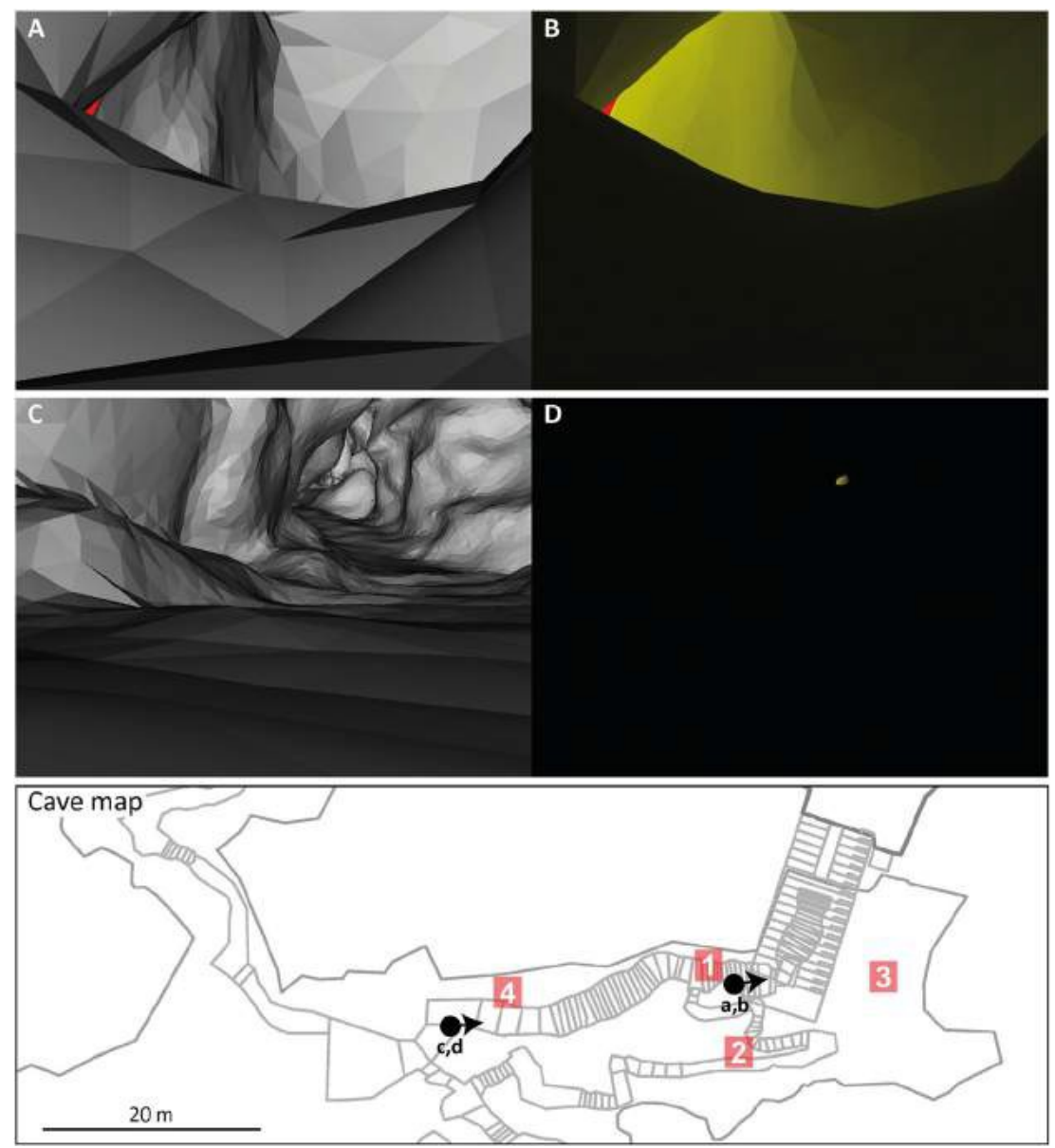

Figure 7. Lighting analysis results by ray tracing (yellow marks indirect light) based on the 3D model with a $10 \mathrm{~cm}$ triangle edge length. Perspective view of the cave nearby the entrance $(A)$, where the sky is still visible (red) and the according simulation result of the area (B). Similarly, the view from the floor of the grand hall and the simulation result is shown $(C$ and $D)$. Both positions and the viewing direction are marked in the cave map. Important archaeological zones are marked with red rectangles. This figure is available in colour online at wileyonlinelibrary.com/journal/arp

integration of local RTK-correction services, or the translation into national surveying networks by transformation (Seeber, 2003). The transformation to the local archaeological surveying network was enabled by the measurements of identical points. This connection was additionally used for the indirect registration by tie points in the caves. Several small reflectors were accurately measured by the total station in the local system, which have been transformed later into the global system and were then used for the registration (Rüther et al., 2009). This quite accurate initial estimation of every position of the TLS is enhanced by the MSA-approach and leads to a relative accuracy $<\sim 1 \mathrm{~cm}$. Overall, detailed topographic maps, plans and cross-sectional profiles of the archaeological sites were successfully established.

Although a large number of scan positions at the site were established, full coverage could not be achieved. The Galerías Altas and several other parts of the Ardales
Cave could unfortunately not be reached during the survey with this equipment. The weight of the instrument prevented recordings of the Galerías Altas, which are only reachable by rock climbing and roping of the instruments. This is an option for future surveys (Buchroithner and Gaisecker, 2009). Likewise, the size of the instrument is not suitable for very narrow parts and this instrument shows a minimum measurement range of $2 \mathrm{~m}$ that is omitted during scanning. For such narrow parts, as well as for climbing, smaller and faster scanners that mostly apply the continuous wave laser measurements, comparing phase differences (Vosselman and Maas, 2010) would be more feasible (Rüther et al., 2012), but show a smaller maximum range. Thus, a combined, repeated survey would be most promising.

The presented distribution of the ceiling thickness of the Ardales Cave, derived by the comparison of the inner and outer TLS measurements is a valuable result. A ceiling thickness of less than $8 \mathrm{~m}$ marks areas for 
further possible entrances, which can be revealed by geoarchaeological prospection. In this case, drillings and georadar profiles have already been conducted for the area above the Galerías Altas and Galería del Arquero (Figure 2). For the Galerías Altas, which cover an area on the top level of the Galería del Arquero and several further areas, similar small or smaller ceiling heights are expected and denoted in previous plans (Ramos et al., 1992). These areas were not covered by our survey due to archaeological and previously mentioned logistic constraints. Rüther et al. (2009) present a similar approach, combining inside TLS and tachymetric measurements with outside tachymetric contour measurements. In contrast, the ceiling thickness was here computed instead of applying manual measurements, similar to Elez et al. (2013). Further investigations by noise or the analysis of thermal imagery (Casana et al., 2014) are needed to prove these findings.

For detailed studies on small structures, the combination with photogrammetric methods was available by using the additionally recorded pictures, thereby allowing a more detailed reconstruction for several areas. Photogrammetric approaches (De Reu et al., 2013) or a combination with triangulation-based scanners and structured-light scanners for a more detailed reconstruction of specific objects is generally an option (Grussenmeyer et al., 2012; Remondino, 2011). A successful integration of the data from the structuredlight scanner was shown here (Figure 3 ). Thus, in addition to the position of rock art in the cave, its significance is shown. Accurate texture mapping with a full coverage without occlusions needs a large amount of manual work (Grussenmeyer et al., 2012; Rüther et al., 2012). Automatic, effective selection procedures for optimal image mapping, show faster and promising results (Al-Khedera et al., 2009; Zalama et al., 2011). However, the automatically acquired pictures enhance orientation in the whole cave model and allow to establish textured models of specific areas (Figure 3). In addition, panoramic images derived from the pictures of one scan position are an additional dataset for the presentation of the cave. Likewise, the calibrated pictures with a known orientation can be used for detailed analysis.

In general, the combination of tachymetric networks and $3 \mathrm{D}$ models derived by TLS measurements is a promising opportunity for further analysis of 3D distributions of archaeological findings and all other geoscientific measurements in the joint 3D GIS, as shown by Katsianis et al. (2008) for an open site. This combination allows the representation of all integrated information. In addition, an enhanced, interactive visualization of the whole environment in virtual reality (VR) (Bruno et al., 2010; Rua and Alvito, 2011) is possible. The fusion of 3D surfaces and further measurements, such as punctual stratigraphic information or georadar transects (Siart et al., 2013) is promising. In this case, the $3 \mathrm{D}$ representation of the distribution of geoscientific and archeological findings helps to understand the complex geological and archaeological morphology.

The new physically based lighting simulation is a promising method to understand light conditions (natural lighting as well as artificial illumination). In this case, it revealed which parts of the cave are directly exposed to sunlight as opposed to areas which are only within reach of indirectly scattered light. Thus, areas that must be lit from artificial light sources can be considered in contrast to areas where direct or indirect daylight is available. In addition, locations where the time of day is observable can be detected. Furthermore, lighting simulations extended by considering artificial illumination based on torches or small oil lamps open up the possibility to analyse the role of the perception and the visibility of cave art (Pastoors and Weniger, 2011).

The lighting simulation was conducted under the assumption that the sun is a distant, ambient light source with equal intensity from all incident directions. This assumption imposes an approximation which is however viable: the sun as a light source is sufficiently far away to be considered as a directional light source, and light rays that originate from the sun are scattered multiple times by the earth's atmosphere. A more thorough simulation of diurnal variation in the spirit of Masuda et al. (2010) could render the outcome of the lighting simulation more precisely and is thus part of our future efforts. The simulation conducted for this contribution provides an upper boundary on the light that is available at certain spots, as well as on its intensity, while a simulation of diurnal variation will further improve the outcome. In contrast to Masuda et al. (2010), whose lighting simulation is based on the radiosity method (Ward, 1994), the lighting simulation used here is based on full global illumination. Global illumination has recently received much attention because implementations allow for nearly interactive content manipulation (Wald et al., 2014). Furthermore, with full global illumination it becomes possible to simulate arbitrary BRDFs. With that, in the future it will, for example, be possible to measure the specific reflectivity properties of the stones in the Ardales Cave and consider those for the simulation.

However, this simulation generally implies several assumptions. For instance, the geometry of the cave is considered here as stable since the Solutrean $(22-17,000$ 
$\mathrm{BP})$, as the cave art is still visible and no evidence for roof collapses are present. It is assumed that the construction of stairways and the entrance building only had a small impact on the geometry of the cave. Past vegetation cover at the outside area was not considered here and the concrete parking area in front of the entrance building was not reshaped. Likewise, further entrances can change the lighting conditions, but the exact position of further entrances is not yet determined. The entrance building (Figure 6), walls and the door, which encloses the cave, are not moveable. Thus, this is the only possibility to assume the sunlight distribution in the cave.

\section{Conclusion}

In this study, TLS was used in combination with other methods for the documentation of the Ardales Cave. However, some constraints, like the minimum range, the measurement time and the weight of the TLS need to be considered in order to achieve a good cover. The accurate georeference of the cave achieved by the RTKGPS measurements allows the location of the data in its broader context of the Iberian Peninsula. Likewise, all other geoscientific data were integrated by the established transformation of the global and local reference system. All data is implemented in a 3D GIS geodatabase. In addition, the detailed records of the structured-light scanner were successfully incorporated and the cave art is now virtually available in the actual context of the cave. This integrative method supports associated geoarchaeological research. The comparison of the two 3D models from the inside and outside area shows locations with a low ceiling thickness and result in possible areas of further entrances. The derived and partly reconstructed 3D models are a requirement for simulations of ancient conditions. In this case, newly developed lighting simulations based on path tracing conducted on the altered 3D model of the cave revealed areas where daylight is perceived. Overall, this integrative approach generally allows a convincing documentation and analysis of geoarchaeological sites.

\section{Acknowledgements}

The authors gratefully acknowledge financial support from the CRC 806 "Our way to Europe - Culture-Environment Interaction and Human Mobility in the Late Quaternary", funded by the Deutsche Forschungsgemeinschaft (DFG). The authors would also like to thank Topcon $\mathrm{GmbH}$
(Germany) and RIEGL Laser Measurement Systems $\mathrm{GmbH}$ (Austria) for continuous support. Juliane Bendig, Nora Tilly, and Jonas Brands supported the survey with great enthusiasm.

\section{References}

Al-Khedera S, Al-Shawabkeh Y, Haala N. 2009. Developing a documentation system for desert palaces in Jordan using 3D laser scanning and digital photogrammetry. Journal of Archaeological Science 36(2): 537-546. DOI:10.1016/j.jas.2008.10.009.

Besl PJ, McKay ND. 1992. A method for registration of 3D shapes. IEEE Transactions on Pattern Analysis and Machine Intelligence 14(2): 239-256.

Blain HA et al. 2013. Climatic conditions for the last Neanderthals: Herpetofaunal record of Gorham's Cave, Gibraltar. Journal of Human Evolution 64(4): 289-299. DOI:10.1016/j.jhevol.2012.11.003.

Bruno F, Bruno S, De Sensi G, Luchi M-L, Mancuso S, Muzzupappa M. 2010. From 3D reconstruction to virtual reality: A complete methodology for digital archaeological exhibition. Journal of Cultural Heritage 11(1): 42-49. DOI:10.1016/j.culher.2009.02.006.

Buchroithner MF, Gaisecker T. 2009. Terrestrial laser scanning for the visualization of complex dome in an extreme alpine cave system. Photogrammetrie Fernerkundung Geoinformation (4): 329-339. DOI:10.1127/1432-8364/ 2009/0025.

Cantalejo P, Mar Espejo MD. 2013. Cueva de Ardales (Málaga, España). Patrimonio prehistórico en el sur de la Península Ibérica. In Pleistocene Foragers on the Iberian Peninsula: Their Culture and Environment, Pastoors A, Auffermann B (eds), Festschrift in honour of Gerd-Christian Weniger for his sixtieth birthday. Neanderthal Museum (Wissenschaftliche Schriften des Neanderthal Museums, 7): Mettmann; 243-260.

Cantalejo P, Maura R, Espejo MM, Ramos J, Medianero J, Aranda A. 2006. La Cueva de Ardales: Arte prehistórico y ocupación en el Paleolitico Superior. Cedma, Diputación de Málaga: Málaga.

Casana J, Kantner J, Wiewel A, Cothren J. 2014. Archaeological aerial thermography: A case study at the Chacoera Blue J community, New Mexico. Journal of Archaeological Science 45: 207-219. DOI:10.1016/j. jas.2014.02.015.

CRC806. 2014. Collaborative Research Centre 806: Our way to Europe. Culture-Environment Interaction and Human Mobility in the Late Quaternary. http:// www.sfb806.uni-koeln.de/ (accessed 15 July 2014).

De Reu J et al. 2013. Towards a three-dimensional costeffective registration of the archaeological heritage. Journal of Archaeological Science 40(2): 1108-1121. DOI:10.1016/j.jas.2012.08.040.

Doneus M, Briese C, Fera M, Janner M. 2008. Archaeological prospection of forested areas using full-waveform airborne laser scanning. Journal of Archaeological Science 35(4): 882-893. DOI:10.1016/j.jas.2007.06.013.

Doneus M, Doneus N, Briese C, Pregesbauer M, Mandlburger G, Verhoeven G. 2013. Airborne laser bathymetry - detecting and recording submerged 
archaeological sites from the air. Journal of Archaeological Science 40(4): 2136-2151. DOI:10.1016/j.jas.2012.12.021.

Elez J et al. 2013. A GIS-based methodology to quantitatively define an adjacent protected area in a shallow karst cavity: The case of Altamira cave. Journal of Environmental Management 118: 122-134. DOI:10.1016/ j.jenvman.2013.01.020.

ESRI Inc. 2014. What is a file geodatabase? http:/ / resources. arcgis.com/en/help/main/10.2/index.html\# / /018s0000 000q000000 (accessed 15 July 2014)

Finlayson C et al. 2006. Late survival of Neanderthals at the southernmost extreme of Europe. Nature 443 (7113): 850-853. DOI:10.1038/nature05195.

González-Aguilera D, Muñoz-Nieto A, Gómez-Lahoz J, Herrero-Pascual J, Gutierrez-Alonso G. 2009a. 3D Digital surveying and modelling of cave geometry: Application to Paleolithic rock art. Sensors 9: 1108-1127. DOI:10.3390/s90201108.

González-Aguilera D, Rodríguez-Gonzálvez P, Gómez-Lahoz J. 2009b. An automatic procedure for co-registration of terrestrial laser scanners and digital cameras. ISPRS Journal of Photogrammetry and Remote Sensing 64(3): 308-316. DOI:10. 1016/j.isprsjprs.2008.10.002.

González-Aguilera D, Muñoz-Nieto A, RodriguezGonzalvez P, Menéndez M. 2011. New tools for rock art modelling: Automated sensor integration in Pindal Cave. Journal of Archaeological Science 38(1): 120-128. DOI:10.1016/j.jas.2010.08.017.

Grussenmeyer PB, Moisan E, Guillemin S, Carozza L, Bourrillon R, Petrognani S. 2012. 3D Multi-scale scanning of the archaeological cave "Les Fraux » in Dordogne (France). In 4th International Conference, Progress in Cultural Heritage Preservation, EuroMed 2012, Ionnadis M, Fritsch D, Leissner J, Davies R, Remondino F, Caffo R (eds). Springer: Heidelberg; 388-395.

Heritage GL, Large ARG. 2009. Laser Scanning for the Environmental Sciences. Chichester: Wiley-Blackwell.

Jennings R, Finlayson C, Fa D, Finlayson G. 2011. Southern Iberia as a refuge for the last Neanderthal populations. Journal of Biogeography 38(10): 1873-1885. DOI:10.1111/j.1365-2699.2011.02536.x.

Kajiya JT. 1986. The rendering equation. In Proceedings of the 13th annual conference on Computer graphics and interactive techniques, ACM; 143-150.

Katsianis M, Tsipidis S, Kotsakis K, Kousoulakou A. 2008. A 3D digital workflow for archaeological intra-site research using GIS. Journal of Archaeological Science 35(3): 655-667. DOI:10.1016/j.jas.2007.06.002.

Kehl M et al. 2013. Late Neanderthals at Jarama VI (central Iberia)? Quaternary Research 80(2): 218-234. DOI:10.1016/j.yqres.2013.06.010.

Kersten TP, Mechelke K, Lindstaedt M, Sternberg H. 2009. Methods for geometric accuracy investigations of terrestrial laser scanning systems. Photogrammetrie Fernerkundung Geoinformation (4): 301-315. DOI:10.1127/ 1432-8364/2009/0023.

Lambers $\mathrm{K}$ et al. 2007. Combining photogrammetry and laser scanning for the recording and modelling of the Late Intermediate Period site of Pinchango Alto, Palpa, Peru. Journal of Archaeological Science 34(10): 1702-1712. DOI:10.1016/j.jas.2006.12.008.

Lerma JL, Navarro S, Cabrelles M, Villaverde V. 2010. Terrestrial laser scanning and close range photogrammetry for 3D archaeological documentation: the Upper Palaeolithic Cave of Parpallo as a case study. Journal of Archaeological Science 37(3): 499-507. DOI:10.1016/j. jas.2009.10.011.

Mårtensson S-G, Reshetyuk Y, Jivall L. 2012. Measurement uncertainty in network RTK GNSS-based positioning of a terrestrial laser scanner. Journal of Applied Geodesy 6(1): 25-32. DOI:10.1515/jag-2011-0013.

Masuda T, Yamada Y, Kuchitsu N, Ikeuchi K. 2010. Illumination Simulation for Archaeological Investigation. In Digitally Archiving Cultural Objects, Ikeuchi K, Miyazaki D (eds). Springer: New York; 419-439.

Pastoors A, Weniger G-C. 2011. Cave art in context: Methods for the analysis of the spatial organization of cave sites. Journal of Archaeological Research 19(4): 377-400. DOI:10.1007/s10814-011-9050-5.

Ramos J, Espejo MM, Cantalejo P. 1992. Cueva de Ardales. Su recuperación y estudio. Ayuntamiento de Ardales: Málaga.

Rantzau DL, Lang R, Nebel H, Wierse A, Ruehle R. 1996. Collaborative and interactive visualization in a distributed high performance software environment. In High Performance Computing for Computer Graphics and Visualisation, Chen M, Townsend P, Vince JA (eds). Springer: London; 207-216.

Remondino F. 2011. Heritage recording and 3D modeling with photogrammetry and 3D scanning. Remote Sensing 3(6): 1104-1138. DOI:10.3390/rs3061104.

Richter J, Melles M, Schäbitz F. 2012. Temporal and spatial corridors of Homo sapiens sapiens population dynamics during the Late Pleistocene and early Holocene. Quaternary International 274: 1-4. DOI:10.1016/j. quaint.2012.06.009.

Riegl LMS GmbH, 2014. Datasheet LMS-Z420i, http:/ /riegl. com/uploads/tx_pxpriegldownloads/10_DataSheet_Z42 0i_03-05-2010.pdf (accessed 15 July 2014).

Rua H, Alvito P. 2011. Living the past: 3D models, virtual reality and game engines as tools for supporting archaeology and the reconstruction of cultural heritage - the case-study of the Roman villa of Casal de Freiria. Journal of Archaeological Science 38(12): 3296-3308. DOI:10.1016/j.jas.2011.07.015.

Rüther $\mathrm{H}$ et al. 2009. Laser scanning for conservation and research of African cultural heritage sites: the case study of Wonderwerk Cave, South Africa. Journal of Archaeological Science 36(9): 1847-1856. DOI:10.1016/j. jas.2009.04.012.

Rüther H, Bhurtha R, Held C, Schroder R, Wessels S. 2012. Laser scanning in heritage documentation: The scanning pipeline and its challenges. Photogrammetric Engineering \& Remote Sensing 78(4): 309316.

Seeber G. 2003. Satellite Geodesy. Walter de Gruyter: Berlin. Shih PT-Y, Chen Y-H, Chen J-C. 2014. Historic shipwreck study in Dongsha Atoll with bathymetric LiDAR. Archaeological Prospection 21: 139-146. DOI:10.1002/ arp.1466.

Siart C, Forbriger M, Nowaczinski E, Hecht S, Höfle B. 2013. Fusion of multi-resolution surface (terrestrial laser scanning) and subsurface geodata (ERT, SRT) for karst landform investigation and geomorphometric quantification. Earth Surface Processes and Landforms 38(10): 1135-1147. DOI:10.1002/Esp.3394. 
Tusa S, di Maida G, Pastoors A, Piezonka H, Weniger G-C, Terberger T. 2013. Grotta di Cala dei Genovesi - new studies on the Ice Age cave art on Sicily. Praehistorische Zeitschrift 88(1-2): 1-22. DOI:10.1515/pz.2013.0001.

Vosselman G, Maas H-G. 2010. Airborne and Terrestrial Laser Scanning. Whittles Publishing: Dunbeath.

Ward GJ. 1994. The RADIANCE lighting simulation and rendering system. Computer graphics. In Proceedings of '94 SIGGRAPH conference, ACM; 143-150.

Wald I, Woop S, Benthin C, Johnson GS, Ernst M. 2014. Embree - a kernel framework for efficient CPU ray tracing. ACM transaction on graphics. In Proceedings of ACM SIGGRAPH 33(4): 143.

Wood RE, Barroso-Ruiz C, Caparros M, Jorda Pardo JF, Galvan Santos B, Higham TF. 2013. Radiocarbon dating casts doubt on the late chronology of the Middle to Upper Palaeolithic transition in southern Iberia. Proceedings of the National Academy of Sciences USA 110(8): 2781-2786. DOI:10.1073/pnas.12076 56110.

Zalama E, Gomez-Garcia-Bermejo J, Llamas J, Medina R. 2011. An effective texture mapping approach for 3D models obtained from laser scanner data to building documentation. Computer-Aided Civil and Infrastructure Engineering 26(5): 381-392. DOI:10.1111/ j.1467-8667.2010.00699.x.

Zielhofer C et al. 2012. The decline of the early Neolithic population center of 'Ain Ghazal and corresponding earth-surface processes, Jordan Rift Valley. Quaternary Research 78(3): 427-441. DOI:10.1016/j.yqres.2012.08.006. 